
application in circular tunnel

${ }^{1}$ College of Civil Engineering, Fuzhou University, Fuzhou 350108, China

${ }^{2}$ Graduate School of Engineering, Nagasaki University, Nagasaki 852-8521, Japan;

${ }^{3}$ State Key Laboratory of Mining Disaster Prevention and Control Co-founded by Shandong Province and the

Corresponding author: Yujing Jiang

Corresponding Address: Bunkyo Machi 1-14, Nagasaki 852-8521, Japan.

Email: jiang@nagasaki-u.ac.jp

Phone: +81-080-3118-5202

Fax: $+0532-86057957$ 


\section{A modified strain-softening model with multi-post-peak behaviors and its application in}

circular tunnel

Abstract: A large number of laboratory experiments have shown that the rocks in post-peak state present strain-softening behaviour under low confining pressure, and gradually evolved into elastic-perfectly plastic with the increasing of confining pressure. Neither the elastic-perfectly plastic model nor the strain-softening model can accurately describe the behavior of rock mass surrounding the deep buried excavations. In this paper, a modified strain-softening model was proposed to describe the non-linear evolution of residual strength under the influence of confining pressure. The new model can realize the gradually transition from strain-softening behaviour to elastic-perfectly plastic behaviour with the increasing of confining pressure. The equivalent residual strength was defined to quantify the strength of rocks in post-peak stage. The parameters involved in the model were estimated via non-linear regression analysis upon a series of stress-strain curves. Based on the plane strain axial symmetry assumption and the incremental theory of plasticity, equilibrium equations and compatibility equations of rock mass around a circular tunnel were deduced. The equations were implemented in the Visual Basic development environment, and a semi-analytical solution was obtained. The influence of post-failure behavior of rock mass was demonstrated through an illustrative case. The distributions of stress, displacement and transitional strength around the tunnel were presented. The differences between the elastic-perfectly plastic model, the strain-softening model and the new model were estimated quantitatively. In addition, the validity of semi-analytical solution was verified by numerical simulations. Parameters analysis showed that the tunnel convergence was influenced by the post-peak behaviour of rock mass dramatically.

Keywords: strain-softening model; post-peak behavior; confining pressure; residual strength; semi-analytical solution

\section{Introduction}

The post-peak behavior is important in engineering practice as the rocks surrounding deep buried excavations (particularly within the excavation damaged zone, EDZ) are basically in 
post-peak state (Hao et al., 2016; Wu et al. 2018). For an effective engineering design, it is necessary to take into account the real mechanical behavior of rocks in post-failure states (Troncone et al., 2014).

A large number of laboratory experiments have been conducted to explore the post-failure behavior of rocks (Fang and Harrison, 2001; Yang et al., 2008; Li et al., 2011; Walton et al., 2015; Cheng et al., 2016; Zimbardo, 2016; Peng et al., 2017). The stress-strain curves obtained in compression tests descended towards a residual state with the increasing of axial strain after attainment of the peak stress (Tiwari et al., 2006; Alejano et al., 2010; Li et al., 2011; Tutluoğlu et al., 2015). The peak strength increased almost linearly with the increasing of confining pressure in most of the laboratory tests. Generally, confining pressure means minimum principal stress $\sigma_{3}$ (Zhang et al., 2018). However, the evolution of residual strength was quite different, which increased more quickly with the increasing of confining pressure (Tiwari et al., 2006; Ma et al., 2014). The rocks present strain-softening features under low confining pressure, while gradually evolved into elastic-perfectly plastic with the increasing of confining pressure (Kaiser et al., 2015).

The transition from brittle to ductile behavior of rocks is a fundamental feature of rock mechanics. An accurate prediction of rock strength is essential for the understanding of many processes encountered in geological sciences and rock engineering (Wang et al., 2002; Wu et al. 2017). However, only elastic-perfectly plastic model or strain-softening model were available to describe the rock behaviors in the past studies (Alonso et al., 2003; Varas et al., 2005). When a tunnel was excavated, the excavation effect could lead to a complex non-uniform stress field around the excavation. Neither the elastic-perfectly plastic model nor the strain-softening model can accurately describe the behavior of rocks surrounding the deep buried excavation. Moreover, few research was found to describe the influence of the multi-post-peak behaviors of rock mass in the ground reaction analyse (Cui et al., 2017).

In order to express the non-linear behaviour of rocks, the mechanical behaviour of the basic elements should be variable under different loading conditions (Saksala et al., 2014; Li et al., 2012). Fang and Harrison (2001) defined a strength degradation index to describe the variation of strength degradation behaviour with different confining pressures. The strength degradation index was expressed as the ratio between the actual strength degradation and maximum strength degradation. However, it is difficult to use the strength degradation index in engineering calculations. The 
81 influence of post-failure behavior of rock mass is still unclear in actual engineering practice. Alejano et al. (2009) introduced three strain softening models including constant strength drop modulus and constant dilatancy, variable drop modulus and constant dilatancy, variable drop modulus and variable dilatancy. The third one was considered to represent a more general behaviour of rock mass. However, the relationship of residual strength and confining pressure is still linearly dependent, which is not coincidence with the actual rock behaviour.

The constitutive equations for rocks in previous studies are unable to express the non-linear evolution of residual strength. Juang et al. (2013) proposed a Bayesian framework using field observations by updating of soil parameters, which gave a revelation to the study of post-failure behavior of rocks. In this paper, a modified strain-softening model was proposed to describe the strength evolution from pre-failure to residual stages considering the influence of confining pressure. The key feature of this model is the gradual transition from strain-softening features to elastic-perfectly plastic with the increasing of confining pressure. The influence of multi-post-failure behaviors was demonstrated in ground reaction analyses.

\section{A modified strain-softening model}

The conventional strain-softening behavior was often simplified to the form of three line segments as shown in Fig. 1. Generally, the rocks exhibiting strain-softening behavior was characterized by a yielding criterion $f\left(\sigma_{i j}, \alpha\right)$ and a plastic potential $g\left(\sigma_{i j}, \alpha\right) . \alpha$ is a softening parameter controlling the gradual transition of rock from a peak failure criterion to a residual one. Herein, the rock is assumed to satisfy the linear Mohr-Coulomb criterion and linear plastic potential. The major principal plastic strain $\varepsilon^{p}$ is employed as the softening parameter. It can be obtained easily from the results of triaxial compression tests. Therefore, the failure criterion $f$ and the plastic potential $g$ can be formulated as follows (Alonso1 et al., 2003; Guan et al., 2007a).

$$
\begin{gathered}
f=\sigma_{1}-K_{p} \sigma_{3}-\sigma_{c}=\left\{\begin{array}{cc}
\sigma_{1}-K_{p} \sigma_{3}-\left(\sigma_{c}^{1}+\frac{\left(\sigma_{c}^{1}-\sigma_{c}^{2}\right) \varepsilon_{1}{ }^{p}}{\alpha \varepsilon_{1 e}}\right) & \left(0 \leq \varepsilon_{1}^{p} \leq \alpha \varepsilon_{1 e}\right) \\
\sigma_{1}-K_{p} \sigma_{3}-\sigma_{c}^{2} & \left(\varepsilon_{1}^{p} \geq \alpha \varepsilon_{1 e}\right)
\end{array}\right. \\
g=\sigma_{1}-K_{\psi} \sigma_{3}=\left\{\begin{array}{lc}
\sigma_{1}-K_{\psi}^{1} \sigma_{3} & \left(0 \leq \varepsilon_{1}^{p} \leq \alpha \varepsilon_{1 e}\right) \\
\sigma_{1}-K_{\psi}^{2} \sigma_{3} & \left(\varepsilon_{1}^{p} \geq \alpha \varepsilon_{1 e}\right)
\end{array}\right.
\end{gathered}
$$

In the above equations, $K_{p}$ is the passive coefficient and remains unchanged within the 
complete plastic region. $K_{p}$ equals to $(1+\sin \varphi) /(1-\sin \varphi)$, where $\varphi$ is friction angle of rock. $\sigma_{c}$ is the compression strength, which changes gradually from ${\sigma_{c}}^{l}$ to $\sigma_{c}^{2}$, according to the evolution of the major principal plastic strain $\varepsilon_{1}^{p}$. $K_{\psi}$ is the dilation factor, and equals to $K_{\psi}{ }^{1}$ and $K_{\psi}^{2}$ for softening region and residual region, respectively.

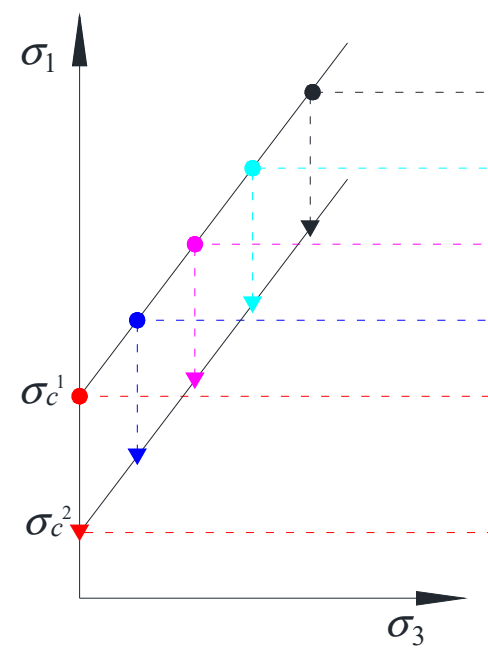

(a)

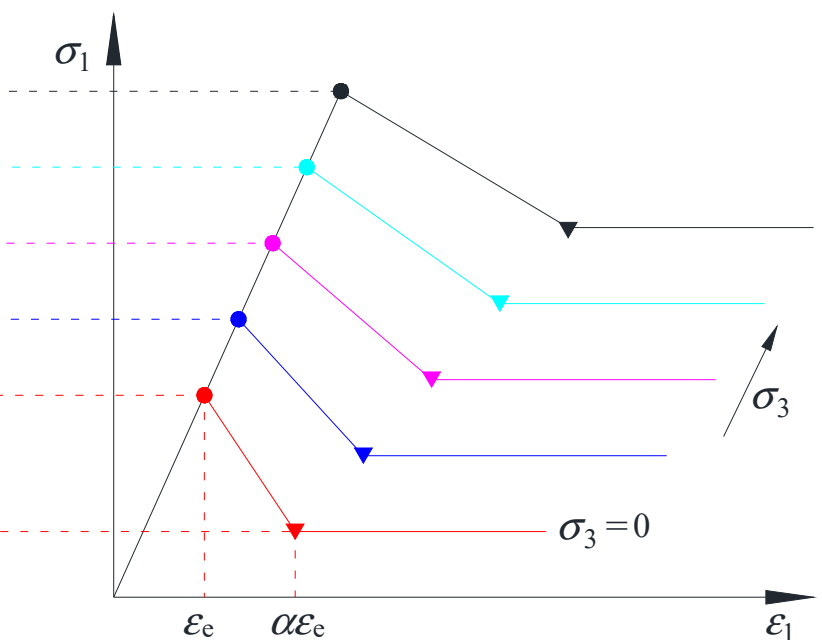

(b)

Fig. 1 Conventional strain-softening model: (a) evolution of strength with confining pressure; (b) constitutive relation

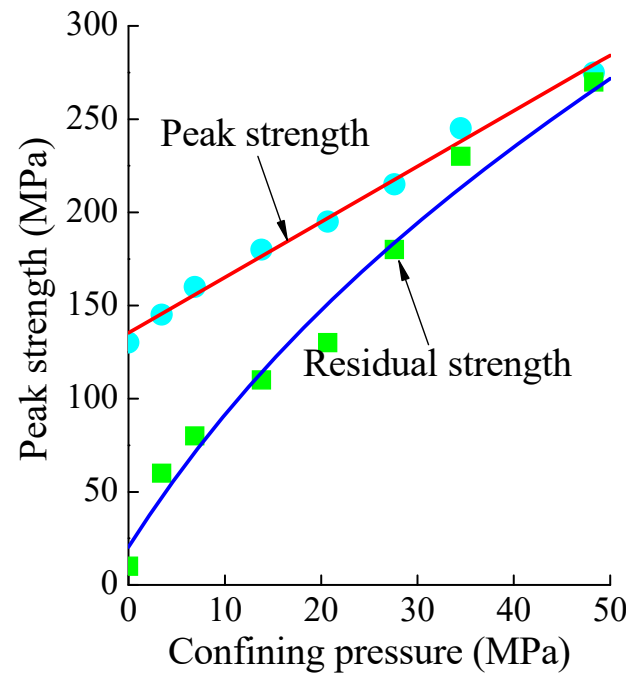

(a)

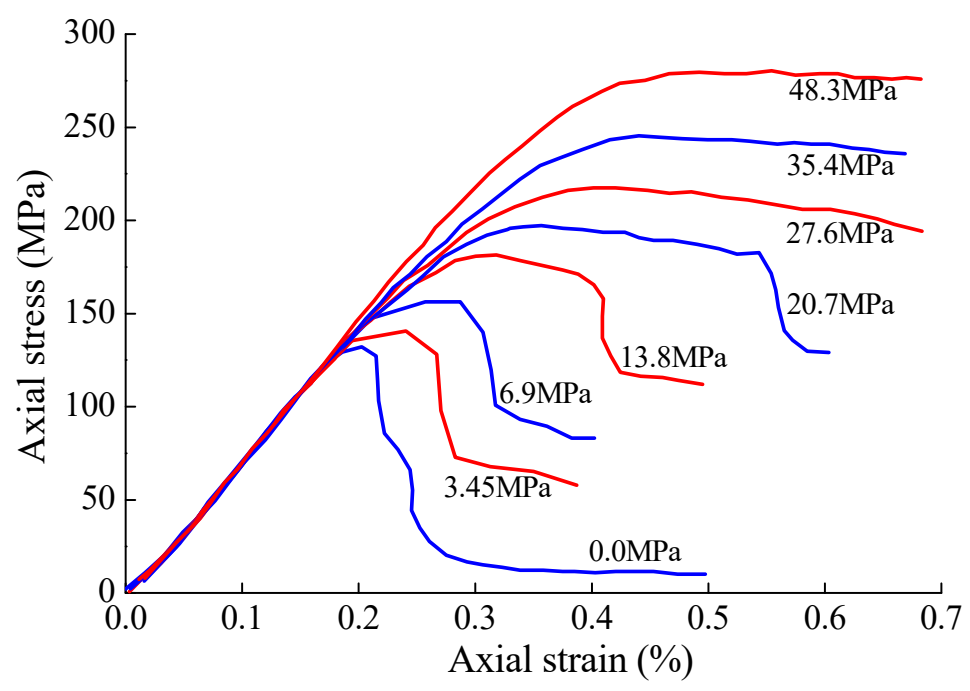

(b)

Fig. 2 Tennessee marble under common triaxial compression: (a) evolution of rock strength with confining pressure; (b) complete axial stress-strain curves (Fang and Harrison, 2001). With the increasing of confining pressure, both the peak strength and residual strength increased linearly in conventional strain-softening model as shown in Fig. 1a. However, the actual behavior is quite different in high confining pressure environment where the rock becomes fully ductile, and showing almost no strength reduction after failure as shown in Fig. 2 (Fang and 
Harrison, 2001; You et al., 2007). Fig. 2b showed a set of stress-strain curves for Tennessee marble obtained in triaxial compression tests with different confining pressures (Fang and Harrison, 2001). The peak strength increased almost linearly with the increasing confining pressure as shown in Fig. 2a. In contrast, the residual strength increased from considerably low values, and approached the peak strength in a non-linear manner. Finally, the rock became fully ductile at high confining pressure, showing almost no strength reduction after failure. Similar behavior was observed in many other test results (You, 2007). These laboratory tests have shown that the residual strength is more sensitive to the increasing of confining pressure than the peak strength. It is necessary to establish a non-linear relationship between the confining pressure and the residual strength.

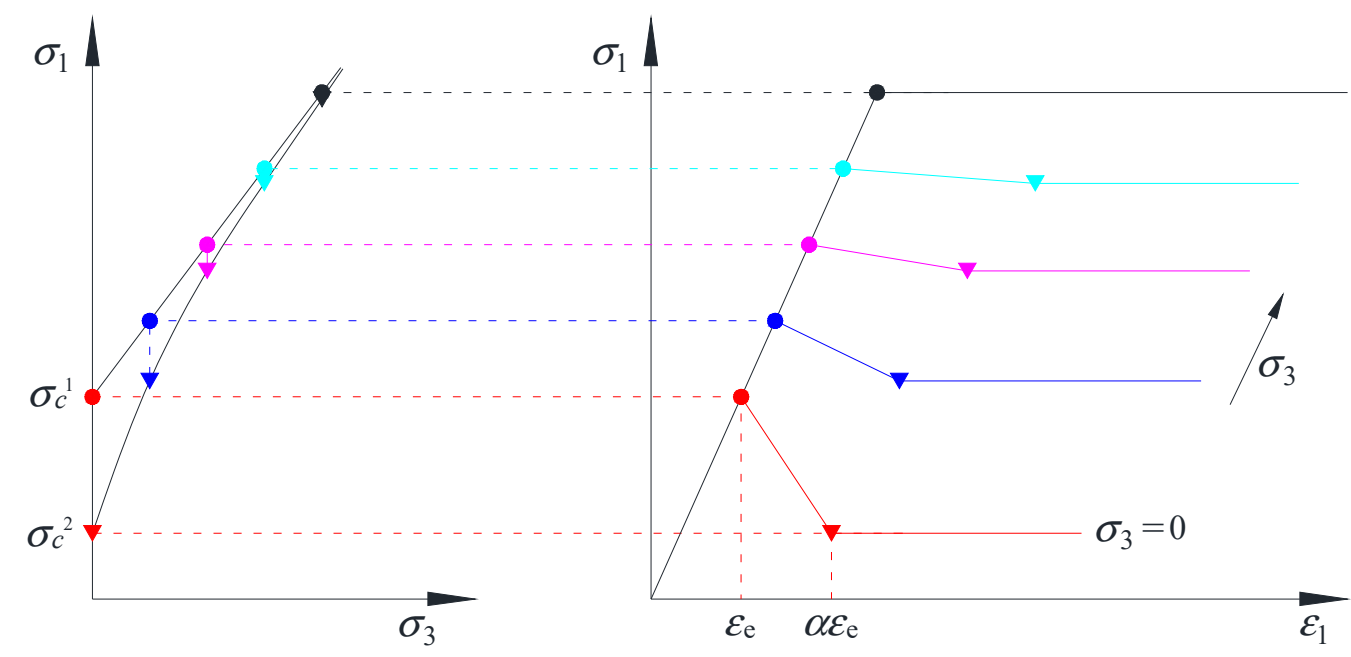

(a)

(b)

Fig. 3 A modified strain-softening model: (a) evolution of strength with confining pressure; (b) constitutive relation.

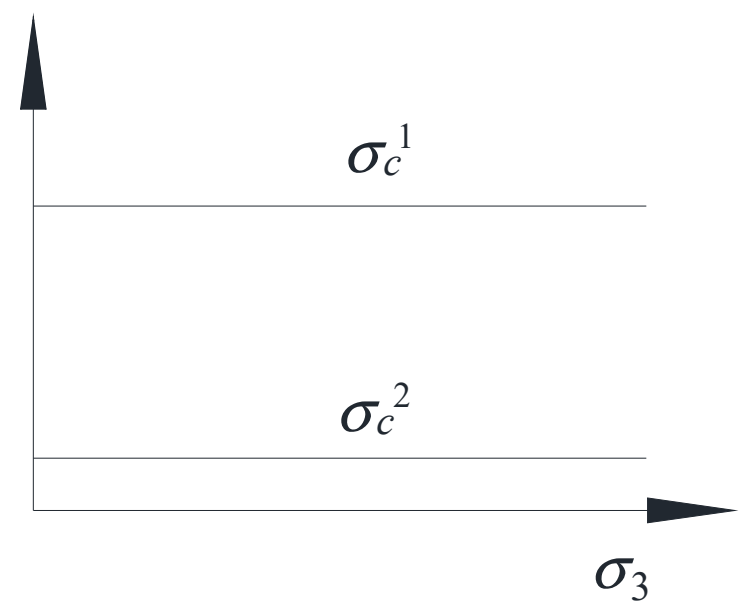

(a)

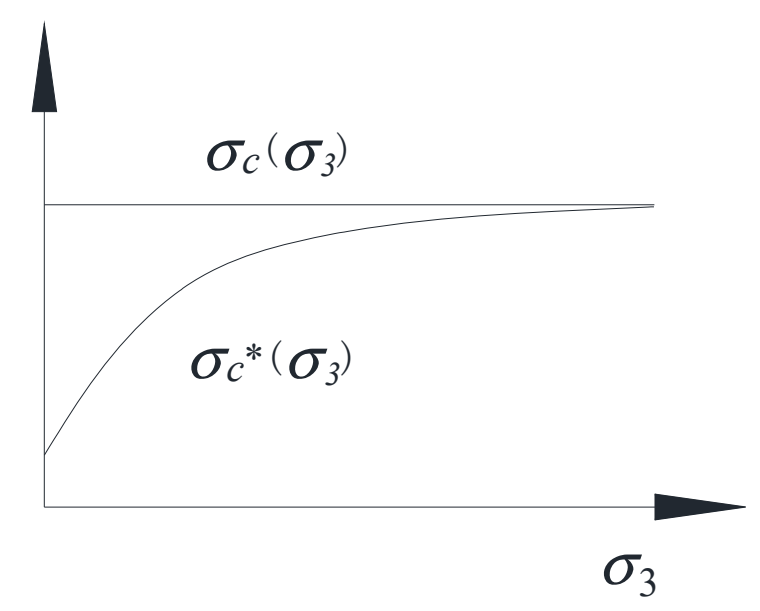

(b)

Fig. 4 The equivalent residual strength of rock: (a) conventional strain-softening model; 
(b) modified strain-softening model.

A modified strain-softening model was proposed to describe the evolution of residual strength with the increasing of confining pressure as shown in Fig. 3. In the new model, the strain-softening behavior was also approximated as three line segments, but the evolution of residual strength was governed by a non-linear equation. In the stage before peak strength, the equation was the same as the conventional strain-softening model.

A new variable was defined as equivalent peak strength $\sigma_{c}\left(\sigma_{3}\right)$ to get rid of the linear influence of confining pressure as shown in equation (3). Similarly, equivalent residual strength $\sigma_{c}{ }^{*}\left(\sigma_{3}\right)$ was defined as shown in equation (4). Fig. 4a shows that both the equivalent peak strength and the equivalent residual strength are constants in the conventional model. In the new model, the equivalent peak strength $\sigma_{c}\left(\sigma_{3}\right)$ is a constant, while the equivalent residual strength $\sigma_{c}{ }^{*}\left(\sigma_{3}\right)$ is a function of confining pressure in the post-failure process as shown in Fig. 4b.

$$
\begin{aligned}
& \sigma_{c}\left(\sigma_{3}\right)=\sigma_{c}-K_{p} * \sigma_{3} \\
& \sigma_{c}^{*}\left(\sigma_{3}\right)=\sigma_{c}^{*}-K_{p} * \sigma_{3}
\end{aligned}
$$

Where, $\sigma_{c}$ is the peak compression strength, and $\sigma_{c}{ }^{*}$ is residual compression strength in laboratory tests. $K_{p}$ is the confinement coefficient, which remains unchanged within the plastic region. $K_{p}$ and $\sigma_{c}\left(\sigma_{3}\right)$ can be obtained by linear regression based on the relation of $\sigma_{1}$ and $\sigma_{3}$ as shown in equation (5).

$$
\sigma_{1}=K_{p} * \sigma_{3}+\sigma_{c}\left(\sigma_{3}\right)
$$

Considering the influence of confining pressure on residual strength, the constitutive relations for the modified strain-softening model can be given as follows:

$$
\sigma_{1}=\left\{\begin{array}{cl}
K_{p} \sigma_{3}+\left(\sigma_{c}\left(\sigma_{3}\right)+\frac{\left(\sigma_{c}\left(\sigma_{3}\right)-\sigma_{c}^{*}\left(\sigma_{3}\right)\right) \varepsilon_{1}^{p}}{\alpha \varepsilon_{1 e}}\right) & \left(0 \leq \varepsilon_{1}^{p} \leq \alpha \varepsilon_{1 e}\right) \\
K_{p} \sigma_{3}+\sigma_{c}^{*}\left(\sigma_{3}\right) & \left(\varepsilon_{1}^{p} \geq \alpha \varepsilon_{1 e}\right)
\end{array}\right.
$$

In the above equations, the compression strength transits gradually from $\sigma_{c}\left(\sigma_{3}\right)$ to $\sigma_{c}{ }^{*}\left(\sigma_{3}\right)$, according to the evolution of the major principal plastic strain $\varepsilon_{l}^{p}$. Herein, the major principal plastic strain $\varepsilon_{l}^{p}$ is employed as the softening parameter, as it can be obtained easily from the results of triaxial compression tests. $K_{p}$ is the passive coefficient.

The equivalent residual strength $\sigma_{c}{ }^{*}\left(\sigma_{3}\right)$ could be estimated based on the laboratory test data in 
existing literatures. Based on laboratory experimental data, it is suggested that the relation between the equivalent residual strength and confining pressure could be expressed by equation (7).

$$
\sigma_{c}^{*}\left(\sigma_{3}\right)=\sigma_{c}\left(\sigma_{3}\right)-\beta * e^{-\gamma * \sigma_{3}}
$$

Where, $\sigma_{c}{ }^{*}\left(\sigma_{3}\right)$ is the equivalent residual strength, $\sigma_{3}$ is the confining pressure, and $\sigma_{c}\left(\sigma_{3}\right)$ is equivalent peak strength. The equivalent residual strength $\sigma_{c}{ }^{*}\left(\sigma_{3}\right)$ for different types of rocks can be calculated by equation (4), and $\sigma_{c}\left(\sigma_{3}\right)$ can be obtained according to equation (5). According to the definition, the values of $\sigma_{c}{ }^{*}\left(\sigma_{3}\right)$ must be less than $\sigma_{c}\left(\sigma_{3}\right)$ and gradually approaching to it. $\beta$ represents the difference between equivalent peak strength and equivalent residual strength when the confining pressure is zero. $\gamma$ is an exponential parameter, which control the transformation speed of residual strength to peak strength. $\beta$ and $\gamma$ could be estimated by curvilinear regression based on a series of stress-strain curves from triaxial compression tests.

For example, the source data for Tennessee marble were obtained by estimating the peak and residual strengths of each stress-strain curve in Fig. 2. According to Eq. (4) and Eq. (5), the equivalent peak strength and equivalent residual strength for Tennessee marble were computed and tabulated in Table 1. The data for other kind of marbles, mudstone, limestone, coal and sandstone were presented in Appendix A. The mathematical relationship of equivalent residual strength and confining pressure was fitted to negative exponential function. The data together with the best-fit curves are shown in Fig. 5. In the case of Tennessee marble, the value of $\beta$ was evaluated as 115.0, and the value of $\gamma$ was evaluated as 0.0443 by curvilinear regression on the data listed in Table 1 . The correlation coefficient for this analyses is 0.8976 .

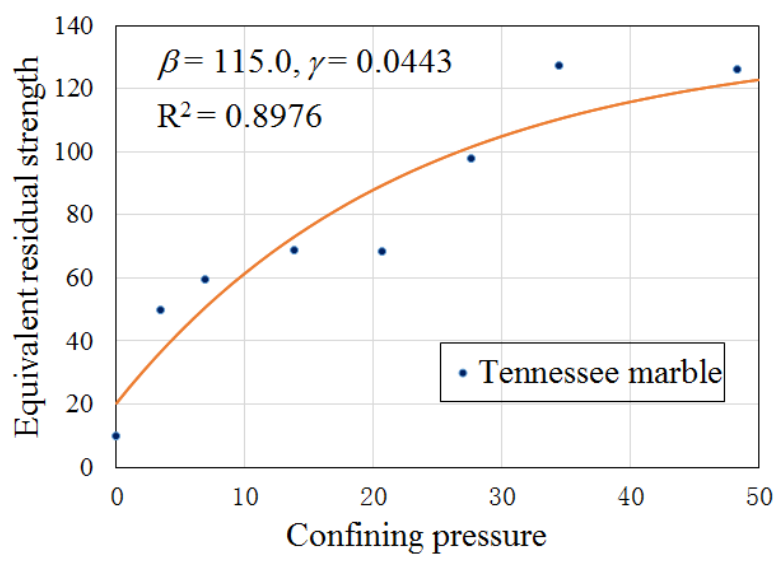

(a)

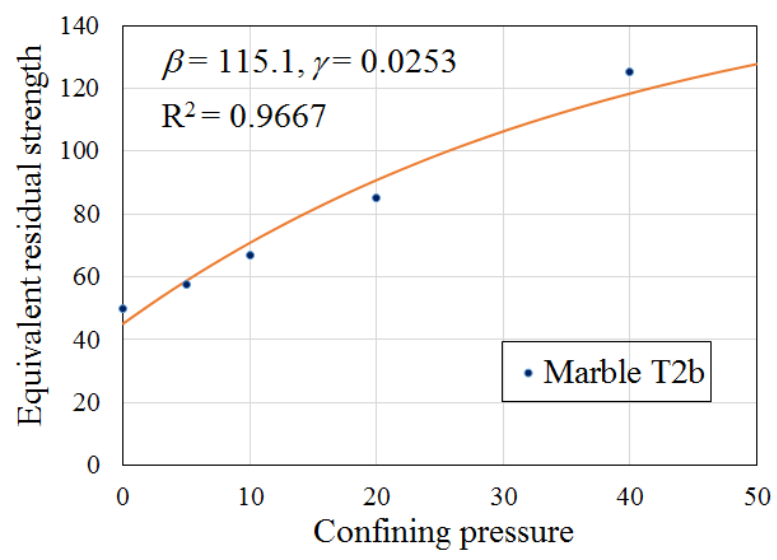

(b) 
188

189

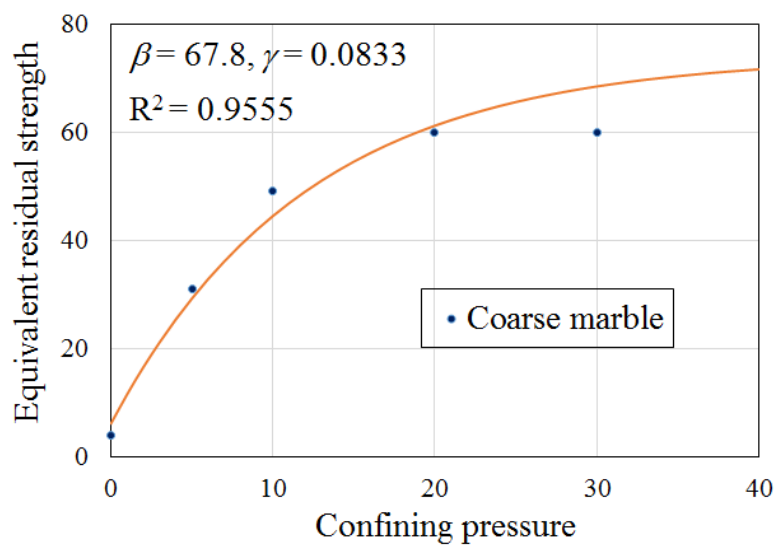

(e)

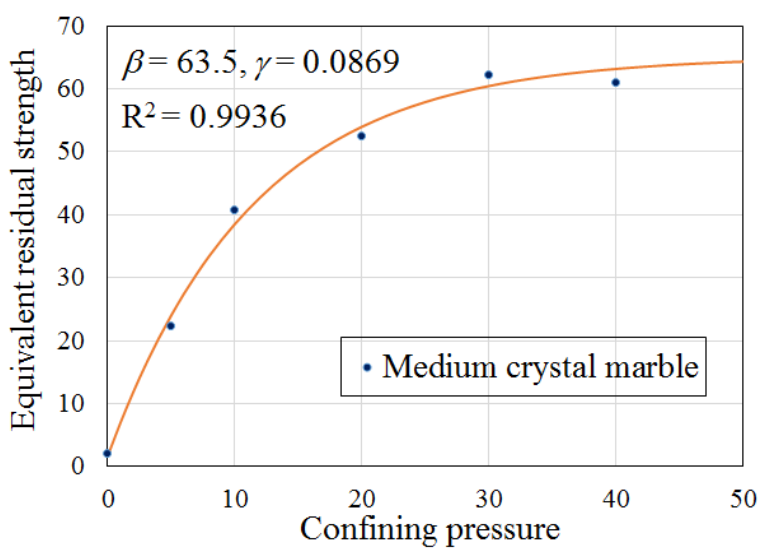

(d)

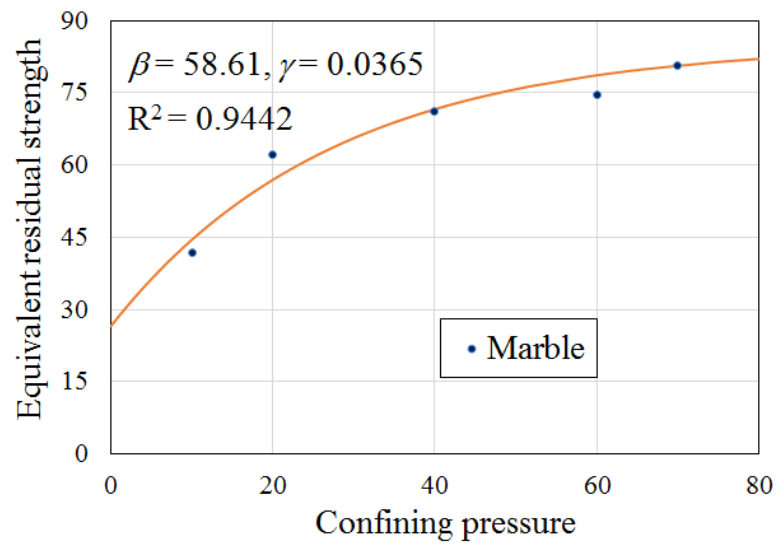

(f)

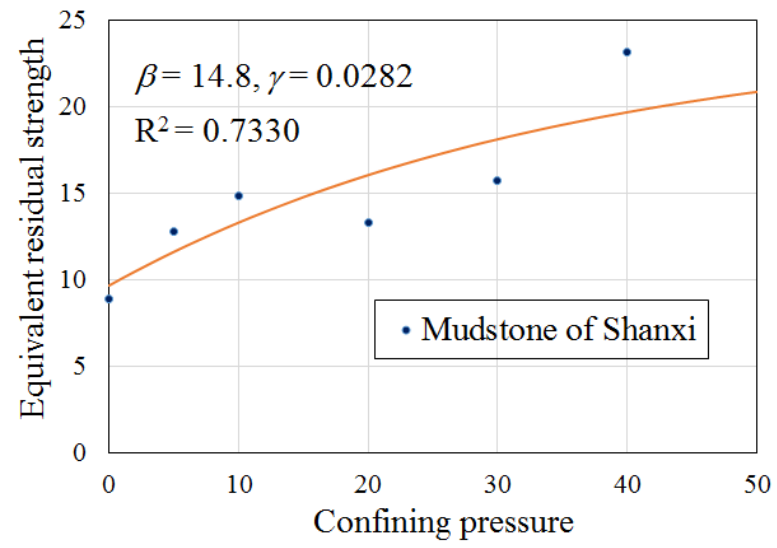

195

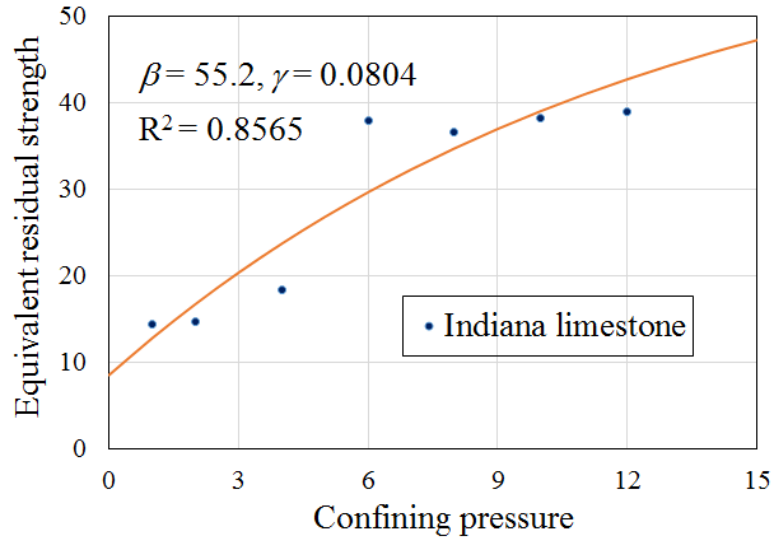

(h) 


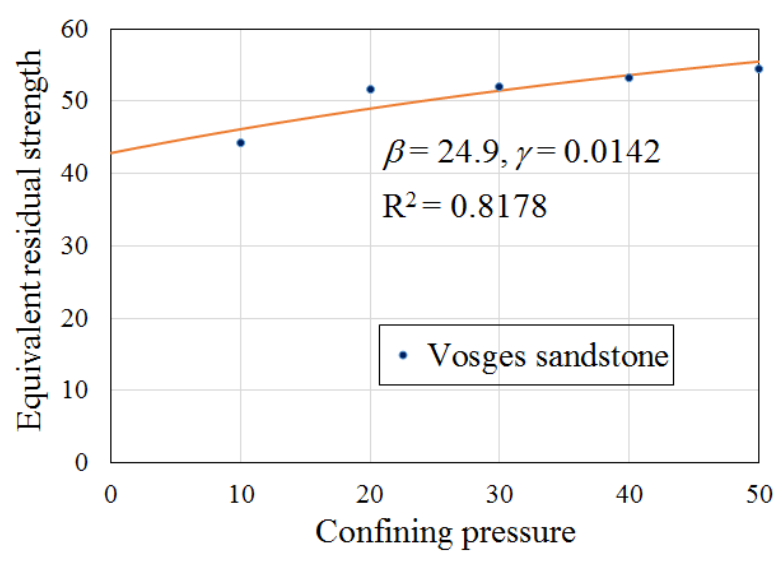

(i)

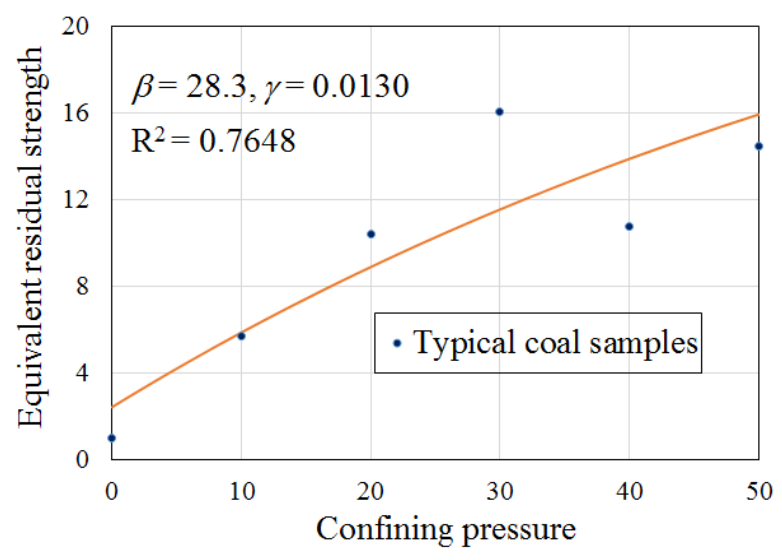

(j)

Fig.5 Variation of equivalent residual strength with confining pressure for different rocks. $\beta, \gamma$ and correlation coefficients for different types of rock were listed in Table 2. According to the mathematical sense of equation (7), $\beta$ represents the difference between equivalent peak strength and equivalent residual strength when the confining pressure is equal to zero. However, the internal instability of residual strength in uniaxial condition resulted that the equivalent residual strength is quite inaccuracy. Therefore, the value of $\beta$ was suggested to be determined by curvilinear regression. The difference between equivalent peak strength and equivalent residual strength is just correlation coefficients were larger than 0.7 for all the samples, which indicated that the correlation between equivalent residual strength and confining pressure was very significant. In addition, the correlation coefficients were relatively higher in the case of marble than the case of mudstone, limestone, sandstone and coal. The results indicated that the relation is more remarkable for hard rock than soft rock. The instability behaviour of soft rock could also be confirmed by the laboratory results by Indraratna (2014). Numerical simulation were conducted to reproduce the post-failure behavior of the tested rock, and a better agreement was observed for the new model, especially under high confining pressure conditions. Therefore, the superiority of new model was verified as shown in Appendix B.

\section{Ground Reaction Analyses of a Circular Tunnel with the New Model}

\subsection{Problem Description}


The proposed model was applied in the ground reaction analyses of a circular tunnel to reveal the influence of post-failure behavior of rock mass on the tunnel convergence. The calculation was 220 developed from the solution for circular tunnels excavated in conventional strain-softening materials by the authors (Guan et al., 2007b). The excavation of long deep tunnels with circular cross section under hydrostatic in-situ stress condition could be considered as an axial symmetry 223 plane strain problem.

\subsection{Equilibrium Equations for Rock Mass}

Consider an infinitesimal volume in the radial direction as shown in Fig. 6, the static equilibrium condition of the infinitesimal rock mass volume can be formulated as following (Guan et al., 2007b).

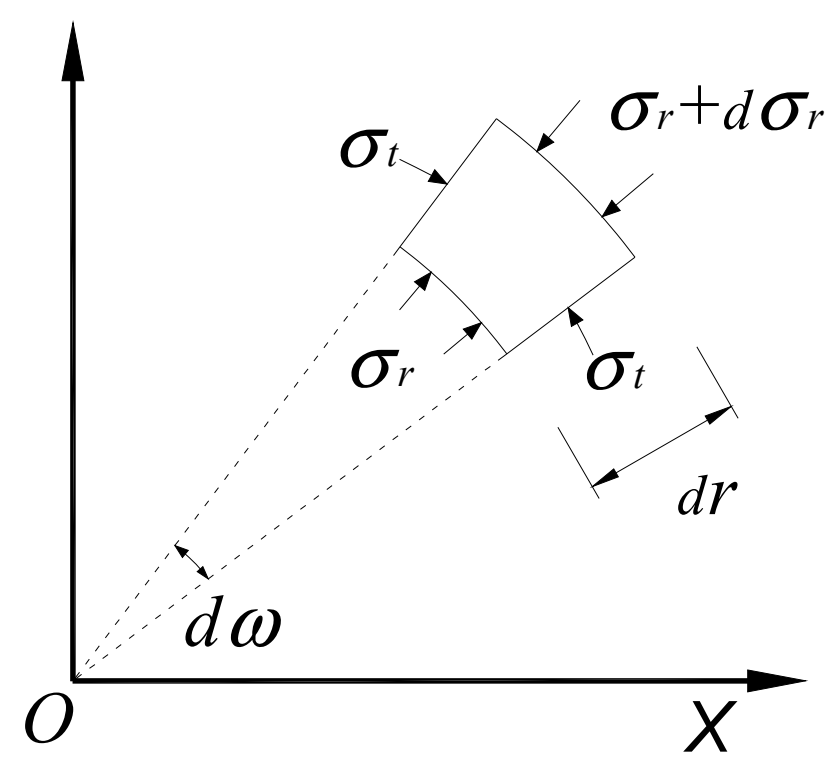

Where, $\sigma_{r}$ is radial stress, $\sigma_{t}$ is tangential stress, $r$ is the radius of the infinitesimal volume, $d \omega$ is the loop angle, $d r$ is the size in the radial direction, $L_{z}$ is the size in the axial direction.

al., 2003), the equilibrium equation can be deduced as:

$$
\sigma_{r} r d \omega L_{z}+2 \sigma_{t} d r L_{z} \sin \frac{d \omega}{2}=\left(\sigma_{r}+d \sigma_{r}\right)(r+d r) d \omega L_{z}
$$

$$
\frac{d \sigma_{r}}{d r}=\frac{\sigma_{t}-\sigma_{r}}{r}
$$

When applying Eq. (9) to the elastic region, where the sum of $\sigma_{r}$ and $\sigma_{t}$ equals $2 P_{0}$, the 
equilibrium equation for elastic region can be formulated as:

$$
\frac{d \sigma_{r}}{d r}=\frac{2 P_{0}-2 \sigma_{r}}{r}
$$

When applying it to the plastic region, where the stress state of rock mass should verify the failure criterion as shown in Eq. (6), the equilibrium equation for the plastic region can be formulated as:

$$
\frac{d \sigma_{r}}{d r}=\frac{\left(K_{p}-1\right) \sigma_{r}+\sigma_{c}}{r}
$$

Where, $\sigma_{c}$ is a varying parameter which is a function of the major principal plastic strain $\varepsilon^{p}$ as shown below:

$$
\sigma_{c}=\left\{\begin{array}{cc}
\sigma_{c}\left(\sigma_{3}\right)+\frac{\left(\sigma_{c}\left(\sigma_{3}\right)-\sigma_{c}^{*}\left(\sigma_{3}\right)\right) \varepsilon_{1}^{p}}{\alpha \varepsilon_{1 e}} & \left(0 \leq \varepsilon_{1}^{p} \leq \alpha \varepsilon_{1 e}\right) \\
\sigma_{c}^{*}\left(\sigma_{3}\right) & \left(\varepsilon_{1}^{p} \geq \alpha \varepsilon_{1 e}\right)
\end{array}\right.
$$

\subsection{Displacement Compatibility Equations for Rock Mass}

Due to the plane strain axial symmetry assumption, the strain-displacement relationships for the rock mass can be simplified significantly as:

$$
\frac{d u}{d r}=\varepsilon_{r} \quad \frac{u}{r}=\varepsilon_{t}
$$

In the elastic region, according to Hook's law, the tangential strain of the rock mass can be evaluated from its stress state, as formulated in Eq. (14), where $E$ and $v$ are the Young's modulus and the Poisson ratio of the rock mass.

$$
\varepsilon_{t}=\left(\frac{\sigma_{t}}{E}-v \frac{\sigma_{r}}{E}-v \frac{2 P_{0} v}{E}\right)-\left(\frac{P_{0}}{E}-v \frac{P_{0}}{E}-v \frac{2 P_{0} v}{E}\right)
$$

Notice that only the strain caused by tunnel excavation is concerned, which means the initial strain due to in-situ stresses should be removed. Then, associating these two equations and considering the hydrostatic in-situ stress condition, the displacement compatibility equation for the elastic region can be formulated as Eq. (15).

$$
u=r \varepsilon_{t}=\frac{P_{0}-\sigma_{r}}{E}(1+v) r
$$

For the plastic region, the loading path in this problem refers to a monotonic decrease of the fictitious inner pressure, corresponding to the advancing of the tunnel face. Consequently, the rates 
of all mechanical variables can be evaluated by their first-order derivatives with respect to $P_{i}$. The incremental theory of plasticity (Graziani et al., 2005) assumes that the total strain rate consists of both elastic part and plastic part, as shown in Eq. (16). The elastic part is controlled by Hooke's law and the plastic part by the potential flow rule, as formulated by Eqs. (17) and (18), respectively. The relationship between the strain rate and the displacement velocity was simplified by virtue of axial symmetry and formulated by Eq. (19).

$$
\begin{gathered}
\dot{\varepsilon}_{r}=\dot{\varepsilon}_{r}^{e}+\dot{\varepsilon}_{r}^{p}, \quad \dot{\varepsilon}_{\theta}=\dot{\varepsilon}_{\theta}^{e}+\dot{\varepsilon}_{\theta}^{p} \\
\dot{\varepsilon}_{r}^{e}=\frac{1-v}{2 G} \dot{\sigma}_{r}-\frac{v}{2 G} \dot{\sigma}_{\theta}, \quad \dot{\varepsilon}_{\theta}^{e}=\frac{1-v}{2 G} \dot{\sigma}_{\theta}-\frac{v}{2 G} \dot{\sigma}_{r} \\
\dot{\varepsilon}_{r}^{p}=\lambda \frac{\partial g}{\partial \sigma_{r}}=\lambda, \quad \dot{\varepsilon}_{\theta}^{p}=\lambda \frac{\partial g}{\partial \sigma_{\theta}}=-\lambda K_{\psi} \\
\dot{\varepsilon}_{r}=\frac{\partial \dot{u}}{\partial r}, \quad \dot{\varepsilon}_{\theta}=\frac{\dot{u}}{r}
\end{gathered}
$$

Here, $g$ is the plastic potential. The rates of all mechanical variables (denoted by a dot mark) are referred as their first-order derivatives with respect to $P_{i}$. Then combining these four equations, eliminating the multiplier $\lambda$, the displacement compatibility equation for the plastic region can be expressed as:

$$
\frac{\partial \dot{u}}{\partial r}+K_{\psi} \frac{\dot{u}}{r}=\frac{\left(1-v-v K_{\psi}\right)}{2 G} \dot{\sigma}_{r}-\frac{\left(v K_{\psi}-K_{\psi}+v\right)}{2 G} \dot{\sigma}_{\theta}
$$

\subsection{Semi-analytical Solution}

The displacement compatibility equation and the equilibrium equation (together with the failure criterion) can only be solved by numerical methods. The fourth order Runge-Kutta method was employed, and a two dimensional finite difference algorithm (i.e. along the unloading path and along the radial direction) was implemented. All the variables describing the state of the surrounding rock mass have two indices: the first indicates a certain stage in the unloading path and the second indicates a certain position in the radial direction. Supposing that at former stage (say the $(k-1)^{\text {th }}$ stage where $\left.P_{i}=P_{i}^{(k-1)}\right)$, all the mechanical states of the rock mass are known, the objective is to evaluate all the mechanical states at current stage (i.e. the $k^{\text {th }}$ stage where $\left.P_{i}=P_{i}^{(k)}\right)$ according to their known counterparts at the former stage. The solution includes the following three steps: stress evaluation, displacement evaluation and transitional strength update. After one iteration finished, 
these known mechanical states at the current stage can be used to evaluate the mechanical states at next stage (i.e. the $(k+1)^{\text {th }}$ stage where $\left.P_{i}=P_{i}^{(k+1)}\right)$, following the same three steps. This kind of iteration was repeated until the final stage where $P_{i}=P_{i}^{f i n}$.

\section{(1) Stress evaluation of rock mass}

The equilibrium equations (10) and (11) were solved by the fourth-order Runge-Kutta method (Basheer, 2000). At the current stage, the radial stress at the tunnel wall $\sigma_{r}\left(k, R_{a}\right)$ is known and equals to $P_{i}^{(k)}$, which serves as the boundary condition of the equilibrium equations. According to Eq. (11) and the failure criterion, the radial and tangential stresses can be obtained by Runge-Kutta method. When the radial stress increases up to the critical inner pressure $P_{i}{ }^{c r i}$, record the position as the radius of the elasto-plastic interface $R_{e}$, then go on evaluating the stress state of elastic region. According to the research of Carranza-Torres (1999), $\sigma_{r e}$ is a constant that only depends on the properties of rock mass itself and independent of the position of the elasto-plastic interface. The critical inner pressure can be calculated by the following formula.

$$
P_{i}^{c r i}=\sigma_{r e}=\frac{2 P_{0}-\sigma_{c}\left(\sigma_{3}\right)}{K_{p}+1}
$$

The radial and tangential stresses at the current stage can be determined after the stress evaluation process.

(2) Displacement evaluation of rock mass

For the elastic region, the radial displacement of the rock mass at the current stage can be evaluated directly by the radial stress of rock mass at the current stage, according to Eq. (15). For the plastic region, the radial and tangential stress rates $\dot{\sigma}_{r}(k, r)$ and $\dot{\sigma}_{t}(k, r)$ should be first evaluated by their first-order difference with respect to $P_{i}$, as shown in Eq. (22).

$$
\dot{\sigma}(k, r)=\frac{\sigma(k, r)-\sigma(k-1, r)}{d P_{i}} \quad\left(r \leq R_{e}\right)
$$

Similarly, the deformation rate at the elasto-plastic interface $\dot{u}\left(k, R_{e}\right)$, which serves as the boundary condition of the compatibility equation, can also be obtained by its first-order difference with respect to $P_{i}$. Then the fourth-order Runge-Kutta method was utilized again to evaluate the deformation rate at each sequential calculation point (inward radial direction) according to the compatibility equations (20). Finally, the displacement at the current stage can be obtained by 
accumulating the displacement increment at the current stage to its counterpart at the former stage.

$$
u(k, r)=u(k-1, r)+\dot{u}(k, r) d P_{i} \quad\left(r \leq R_{e}\right)
$$

The displacement and the stresses at the former stage, as well as the stresses at the current stage, are required during this step. Then the displacement at the current stage can be determined after the displacement evaluation process.

(3) Transitional strength update of rock mass

After the displacement evaluation, the major principle plastic strain $\varepsilon_{t}^{p}$ at the current stage, which serves as the softening parameter, can be evaluated by Eq. (24). Then the transitional strength at the current stage can be computed via Eq. (6) and Eq. (7).

$$
\varepsilon_{t}^{p}(k, r)=\varepsilon_{t}(k, r)-\varepsilon_{t e}(k, r)=\frac{u(k, r)}{r}-\frac{u\left(k, R_{e}\right)}{R_{e}} \quad\left(r \leq R_{e}\right)
$$

The displacements and the tangential stresses at the current stage are required in this step, and the transitional strength of rock mass at the current stage can be determined.

After these three steps, all the mechanical states at the current stage are known, which can be used to evaluate their counterparts at next stage (i.e. the $(k+1)^{\text {th }}$ stage where $P_{i}=P_{i}^{\left({ }^{(k+1)}\right)}$.

\section{Application and Verification of the New Model}

The proposed analytical method was programmed in VB development environment, and verified by numerical simulations. An illustrative case study was presented in this section to demonstrate the influence of post-failure behavior in conventional tunnelling. Supposing that a circular tunnel with a design radius of $5.0 \mathrm{~m}$ was excavated under a hydrostatic in-situ stress of 10 $\mathrm{MPa}$ (about $500 \mathrm{~m}$ rock mass covering above). The properties of the rock mass employed were listed in Table 3.

Fig. 7 showed the ground responses after excavation obtained by the analytical solution (including the distribution of stress, displacement, and transitional strength, represented by solid lines, Analytical_New). To highlight the influence of the different constitutive model, the ground responses with the elastic-perfectly plastic model (Analytical_Ideal) and the conventional strain-softening model (Analytical_SS) were also calculated and represented in these figures. 


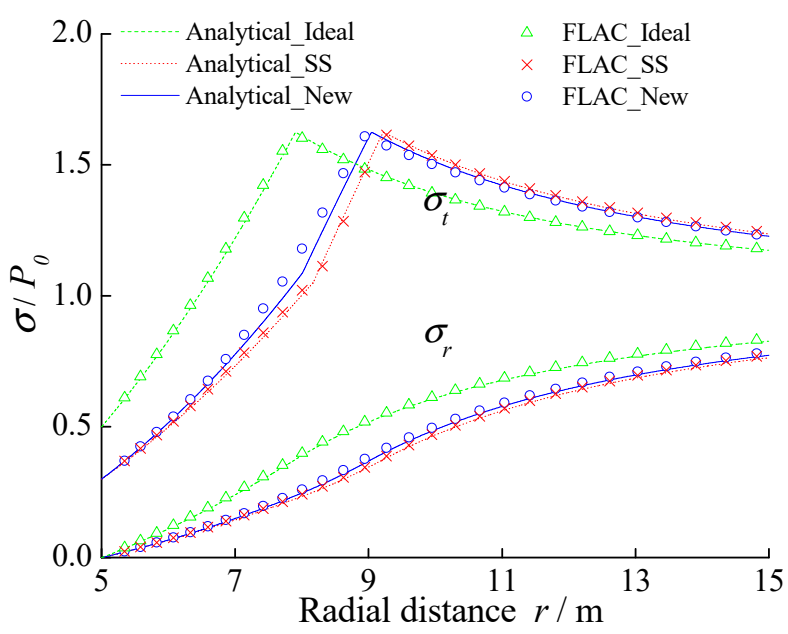

(a)

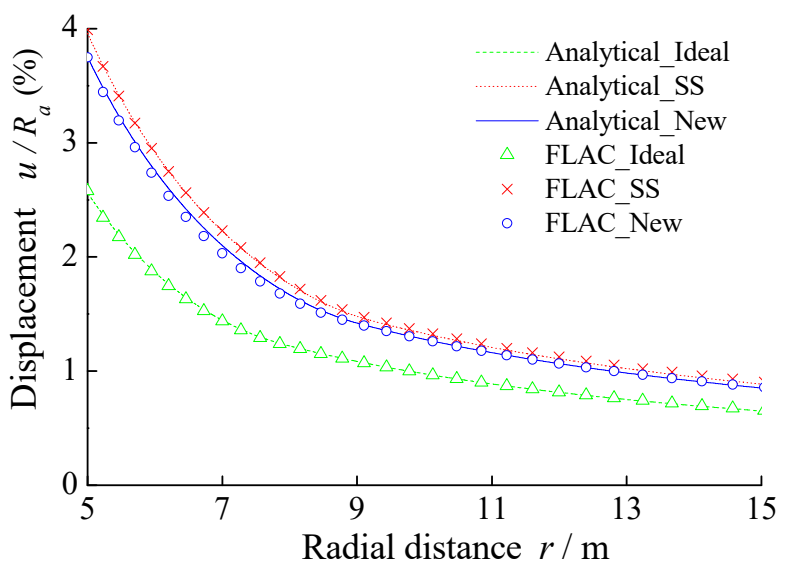

(b)

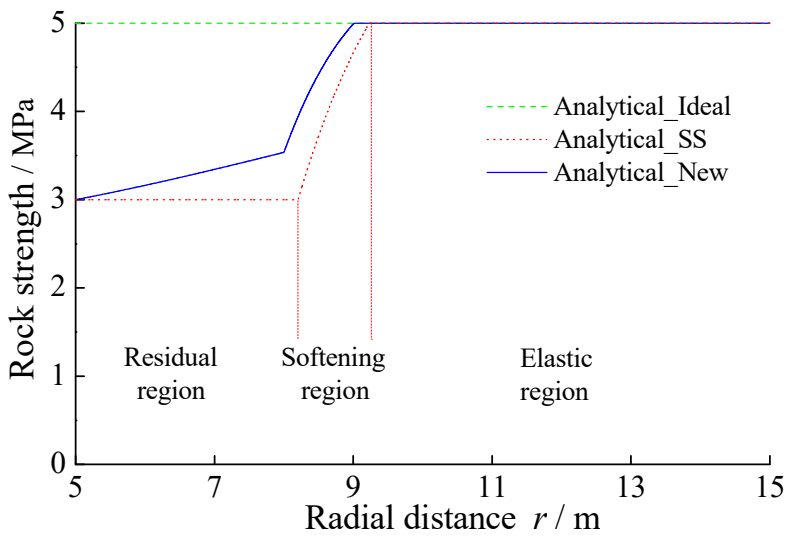

(c)

Fig. 7 Ground responses of a circular tunnel: (a) stress distributions; (b) displacement distributions; (c) transitional strength distributions.

The analytical results showed that the plastic region and the displacement from the new model fall between the elastic-perfectly plastic and the conventional strain-softening solution. For the new model, the plastic region and the displacement is smaller than the conventional strain-softening 
model due to the increasing of post-peak strength. In this calculation case, the difference in the maximum displacements is about $5 \%$. Although the value is not very large compared with the actual error between the theoretical results and measured data, eliminating the system errors is a meaningful work. The influence rules of various parameters on the deformation and failure of rock mass will be revealed in the following parameters analysis.

As shown in Fig. 7c, the equivalent transitional strength in the elastic region is constant, and no softening appears. The equivalent transitional strength distributions in the surrounding rock mass is influenced by the confining pressure and the principal plastic strain in the plastic region. The plastic region is divided into residual region and softening region according to the principal plastic strain. In the residual region, the equivalent transitional strength is constant in the conventional strain-softening model. While, the equivalent transitional strength increases with the increasing of confining pressure $\left(\sigma_{r}\right)$ in the modified strain-softening model.

The validity of analytical method was verified by numerical simulations (codes: FLAC ${ }^{3 \mathrm{D}}$ ). The new model in the numerical simulations was developed based on the strain-softening model by the Fish language in $\mathrm{FLAC}^{3 \mathrm{D}}$. The transitional strength was updated according to the stress and deformation state of every element after every step. The results from the numerical simulations were represented in Fig. 7 (denoted by triangle, cross and circle marks for three different models respectively). As shown in these figures, the ground responses computed by the analytical method and by the numerical simulations fit each other almost exactly.

\section{Parameters Analysis}

Parameters analysis was performed to study the influence of different parameters in the new model quantitatively. The studied parameters included the equivalent peak strength $\sigma_{c}(0)$, the equivalent residual strength $\sigma_{c}^{*}(0)$ and the exponential factor $\gamma$. Taking the illustrative case above as a standard one and varying a single parameter, the relative influence of different parameters on the deformation and failure characteristics of rock mass was illustrated.

The tunnel convergence was selected as the estimation index. The error between the results of strain-softening model and the new model was defined as Eq. (25), which physically stranded for the ratios of tunnel convergence. 


$$
e r r_{\max }=\frac{u_{S S}-u_{N e w}}{u_{S S}}
$$

380 Where, $u_{s s}$ is the maximum tunnel convergence with strain-softening model, $u_{\text {New }}$ is the maximum tunnel convergence with the new model.

\subsection{The Influence of Equivalent Peak Strength}

The equivalent peak strength of rock mass was selected to study its influence on the tunnel convergence. As the equivalent residual strength was $3 \mathrm{MPa}$ in the standard case, the equivalent peak strength was set from $3 \mathrm{MPa}$ to $17 \mathrm{MPa}$ in the following examples. Meanwhile, the other parameters were the same with the standard case.

The evolution of the maximum displacement with the increasing of equivalent peak strength is shown in Fig. 8a. To highlight the difference, the result of the strain-softening model and the $e r r_{\max }$ were also calculated and depicted in this figure. In the strain-softening model, the peak strength $\sigma_{c}{ }^{1}$ and the residual strength $\sigma_{c}^{2}$ are considered to be equal to the equivalent peak strength $\sigma_{c}(0)$ and the equivalent residual strength $\sigma_{c}^{*}(0)$, respectively.

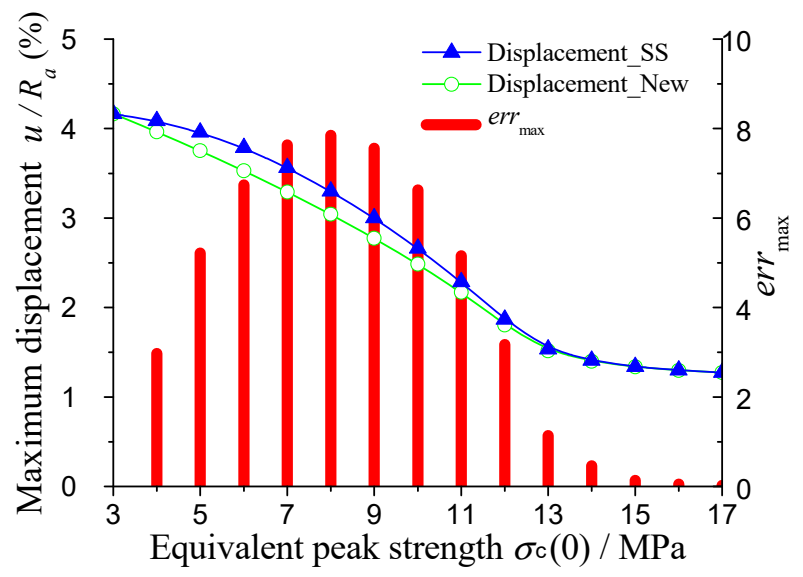




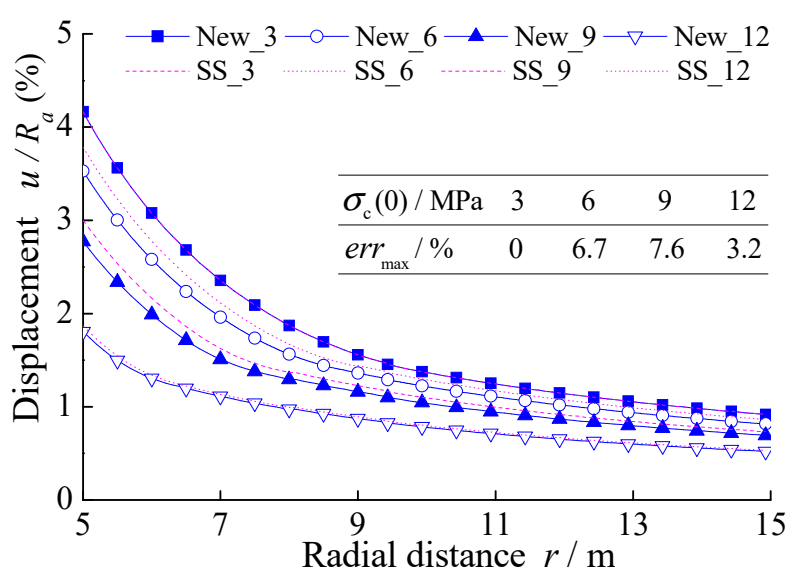

(b)

Fig. 8 The influence of equivalent peak strength: (a) evolution of the maximum displacement and the error; (b) displacement distribution of some typical cases.

The results showed that the maximum displacement in both models decreased gradually with the increasing of equivalent peak strength. The errmax increased first and then decreased, and reach the maximum value for $\sigma_{c}(0)=8 \mathrm{MPa}$. When the equivalent peak strength is very low, the difference between the equivalent peak strength and the equivalent residual strength is very small, which certainly resulting in a small err max value. When the equivalent peak strength is very high, the plastic zone is very small. Therefore, the influence of post peak behaviors decreased, which resulting in a small err max value. The displacement distribution of some typical cases in the surrounding rock mass are shown in Fig. 8b. This figure showed that the displacement difference between the two models mainly located in the plastic zone.

\subsection{The Influence of Equivalent Residual Strength}

The influence of equivalent peak strength was studied in this part. As the equivalent peak strength is $5 \mathrm{MPa}$ in the standard case, the equivalent residual strength was set from $0 \mathrm{MPa}$ to $5 \mathrm{MPa}$ in the following examples. The other parameters were also same with the standard case. The evolutions of the maximum displacement and the err max with the increasing of equivalent residual strength are shown in Fig. 9a. 


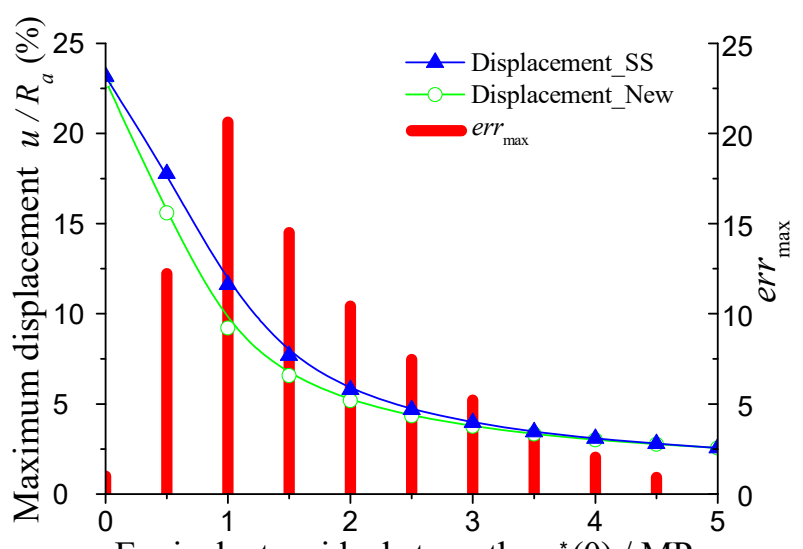

(a)

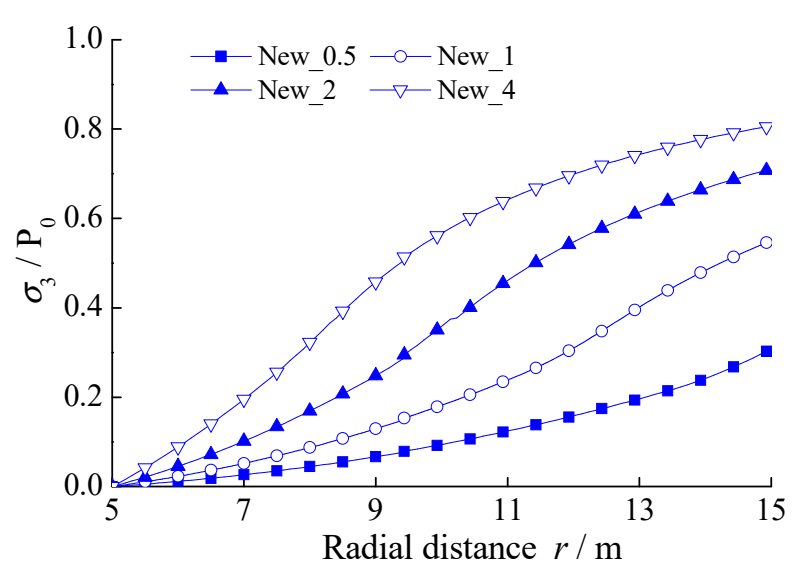

(b)

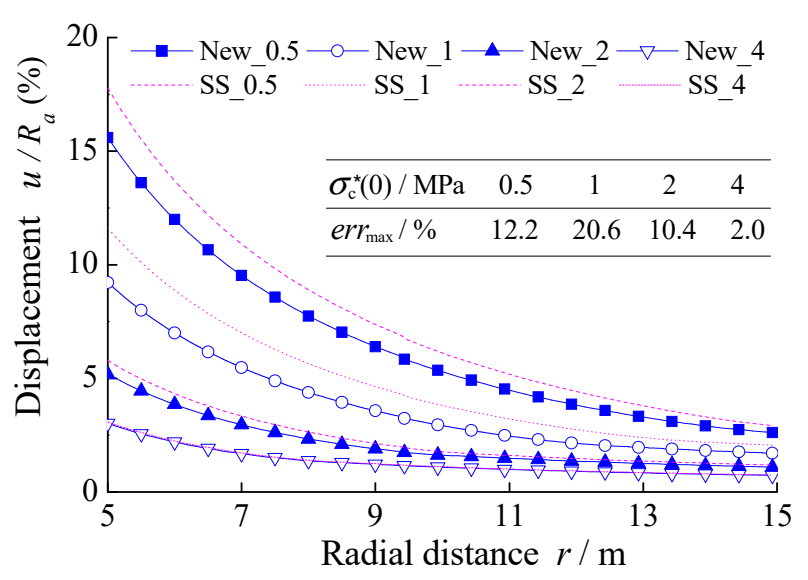

(c)

419 Fig. 9 The influence of equivalent residual strength: (a) evolution of the maximum displacement and the error; (b) distributions of confining pressure; (c) displacement distributions of some typical cases.

The results showed that the maximum displacement decreased sharply with the increasing of equivalent residual strength. The err max increased first and then decreases, and reached the 
maximum value at the stage of $1 \mathrm{MPa}$. When the equivalent residual strength was close to the equivalent peak strength (5MPa), the small difference also resulted in small errmax value. However, when the equivalent residual strength was small (between $0 \mathrm{MPa}$ and $1 \mathrm{MPa}$ ), meanwhile the difference was very large, the errmax also became smaller. This behaviour depends on the small value of confining pressure in case of small equivalent residual strength as shown in Fig. 9b. The displacement distributions of some typical cases in the surrounding rock mass are shown in Fig. 9c.

\subsection{The Influence of Exponential Factor}

The influence of exponential factor was studied in this part. It was set from 0.01 to 10 in the following examples. The other parameters were also the same with the standard case. The evolutions of the maximum displacement and the $e r r_{\max }$ with the increasing of equivalent residual strength are shown in Fig. 10a. The results of elastic-perfectly plastic model and strain-softening model are also shown in this figure.

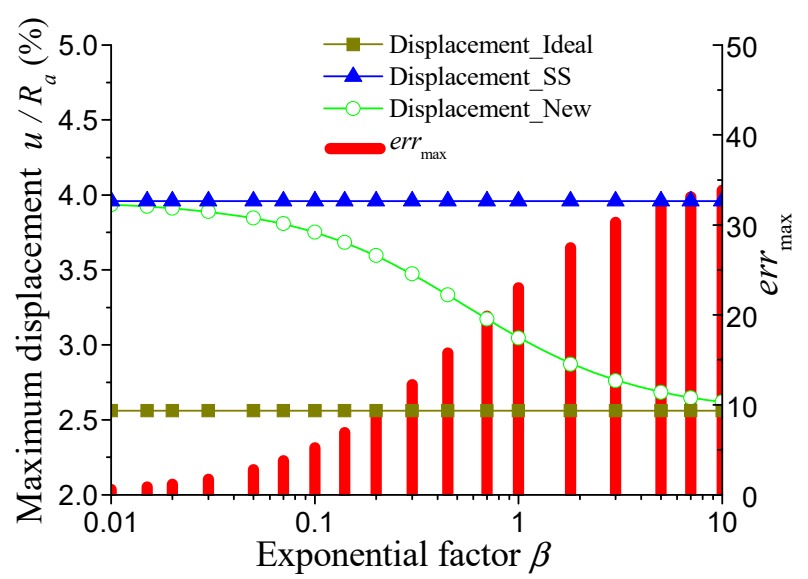

(a)

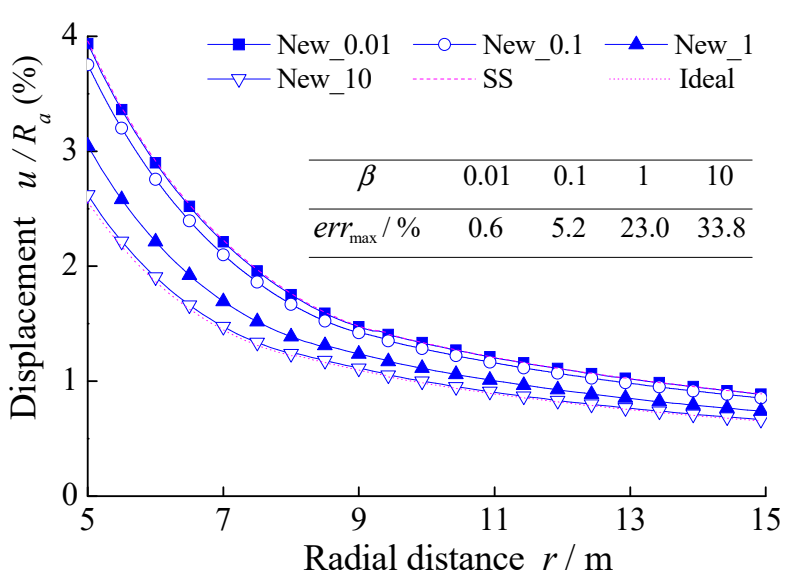




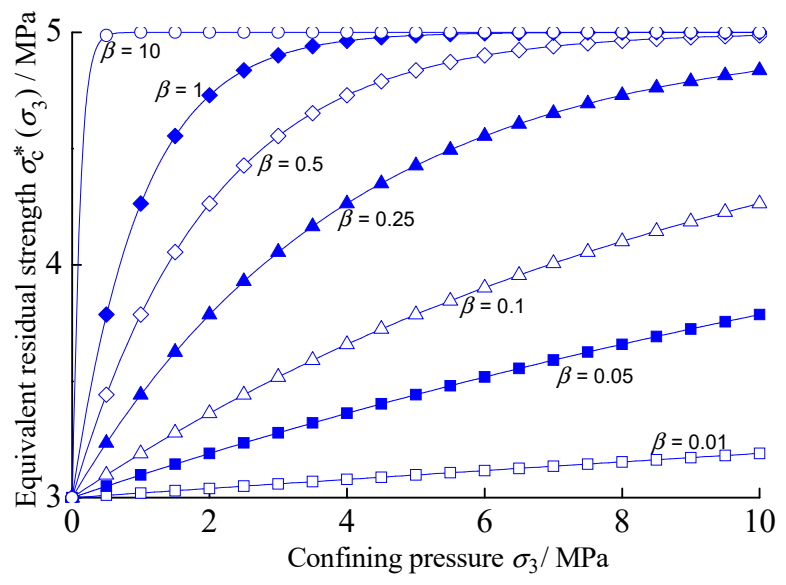

(c)

Fig. 10 The influence of exponential factor: (a) evolution of the maximum displacement and the error; (b) displacement distribution of some typical cases; (c) distributions of equivalent residual strength for different value of exponential factors.

The results showed that the maximum displacement from the new model decreased gradually with the increasing of exponential factor. The error between the results of strain-softening model and the new model $e r r_{\max }$ increased monotonously. There was a clearly trend that the maximum displacement from the new model gradually approaching the elastic-perfectly plastic model from the strain-softening model with the increasing of exponential factor. This behaviour can also be seen in Fig. 10b. It can be explained by the distribution of equivalent residual strength with different value of exponential factor as shown in Fig. 10c. The essential difference of the new model and the elastic-perfectly plastic model, the strain-softening model was herein revealed.

The results above showed that the post-peak behaviour of rock mass influenced the tunnel convergence dramatically. According to parameter studies, the error between the results of strain-softening model and the new model was estimated to range from $0 \%$ to $35 \%$ in common conditions.

\section{Conclusions}

A modified strain-softening model was proposed to describe the non-linear evolution of residual strength of rock mass under the influence of confining pressure. The new model can simulate the gradually transition from strain-softening features to elastic-perfectly plastic with the increasing of confining pressure.

In the new model, equivalent residual strength was defined to describe the actual behaviour of 
rocks. Based on the laboratory test data, the relation between the equivalent residual strength and confining pressure was represented by a negative exponential function. The parameters were estimated by curvilinear regression based on a series of stress-strain curves under common triaxial compression. The values of correlation coefficient were greater than 0.7 for all the rock samples, which indicated that the correlation between equivalent residual strength and confining pressure was very significant.

Based on the plane strain axial symmetry assumption and the incremental theory of plasticity, equilibrium equations and compatibility equations of rock mass around a circular tunnel were deduced theoretically. The equations were programmed in the Visual Basic development environment, and a semi-analytical solution was achieved. The influence of post-failure behavior of rocks was demonstrated through an illustrative case study. The distribution of stress, displacement, and transitional strength around the circular tunnel were presented. The differences between the elastic-perfectly plastic model, the strain-softening model and the new model was estimated quantitatively. In addition, the validity of proposed method was verified by numerical simulations.

Parameters analysis showed that the post-peak behaviour of rock mass influenced the tunnel convergence dramatically. According to parameter studies, the error between the results of strain-softening model and the new model was estimated to range from $0 \%$ to $35 \%$ in common conditions. 
482 Acknowledgments

483 This study is funded by the National Natural Science Foundation of China (No. 51379117). 


\section{Reference}

Alonso, E., Alejano, L.R., Varas, F., Fdez-Manin G., Carranza-Torres C., 2003. Ground response curves for rock masses exhibiting strain-softening behaviour. Int. J. Numer. Anal. Meth. Geomech. 27, 1153-1185.

Alejano, L.R., Rodriguez, D.A., Alonso, E., Fdez-Manin, G., 2009. Ground reaction curves for tunnels excavated in different quality rock masses showing several types of post-failure behaviour. Tunn. Undergr. Sp. Technol. 24, 689-705.

Alejano, L.R., Alonso, E., Rodriguez, D.A., Fernandez, M.G., 2010. Application of the convergence-confinement method to tunnels in rock masses exhibiting Hoek-Brown strain-softening behaviour. Int. J. Rock Mech. Min. Sci. 47, 150-160.

Basheer, I., Hajmeer, M., 2000. Artificial neural network: fundamentals, computing, design and application. J. Microbiol. Meth. 43(1), 3-31.

Besuellea, P., Desruesb, J., Raynaud, S., 2000. Experimental characterisation of the localisation phenomenon inside a Vosges sandstone in a triaxial cell. Int. J. Rock Mech. Min. Sci. 37, $1223-1237$.

Carranza-Torres C., Fairhurst, C., 1999. The elasto-plastic response of underground excavations in rock masses that satisfy the Hoek-Brown failure criterion. Int. J. Rock Mech. Min. Sci. 36(6), 777-809.

Cheng, C., Chen, X., Zhang, S., 2016. Multi-peak deformation behavior of jointed rock mass under uniaxial compression: Insight from particle flow modeling. Eng. Geol. 213(4), 25-45.

Cui, L., Zheng, J.J., Dong, Y.K., Zhang, B., Wang, A., 2017. Prediction of critical strains and critical support pressures for circular tunnel excavated in strain-softening rock mass. Eng. Geol. 224, $43-61$.

Fang, Z., Harrison, J.P., 2001. A mechanical reduction index for rock. Int. J. Rock. Mech. Min. Sci. 38(8), 1193-1199.

Graziani, A., Boldini, D., Ribacchi, R., 2005. Practical estimate of deformations and stress relief factors for deep tunnels supported by shotcrete. Rock Mech. Rock Eng. 38(5), 345-372.

Guan, Z.C., Jiang, Y.J., Tanabasi, Y., 2007a. Reinforcement mechanics of passive bolts in conventional tunnelling. Int. J. Rock Mech. Min. Sci. 44(4), 625-636.

Guan, Z.C., Jiang, Y.J., Tanabasi, Y., 2007b. Ground reaction analyses in conventional tunneling 
excavation. Tunn. Undergr. Sp. Technol. 22(2), 230-237.

Hao, X.J., Feng, X.T., Yang, C.X., Jiang, Q., Li, S.J., 2016. Analysis of EDZ development of columnar jointed rock mass in the Baihetan diversion tunnel. Rock Mech. Rock Eng. 49, $1289-1312$.

Indraratna, B., Nimbalkar, S., Coop, M., Sloan, S.W., 2014. A constitutive model for coal-fouled ballast capturing the effects of particle degradation. Comput. Geotech. 61, 96-107.

Jiang, Y., Yoneda, H., Tanabashi, Y., 2001. Theoretical estimation of loosening pressure on tunnels in soft rocks. Tunn. Undergr. Sp. Technol. 16(2), 99-105.

Juang, C.H., Luo, Z., Atamturktur, S., Huang, H., 2013. Bayesian Updating of Soil Parameters for Braced Excavations Using Field Observations. J. Geotech. Geoenviron. 139(3), 395-406.

Kaiser, P.K., Kim, B.H., 2015. Characterization of Strength of Intact Brittle Rock Considering Confinement-Dependent Failure Processes. Rock Mech. Rock Eng. 48, 107-119.

Li, W., Li, S., Feng, X., 2011. Study of post-peak strain softening mechanical properties of rock based on Mohr-Coulomb criterion. Chin. J. Rock. Mech. Eng. 30(7), 1460-1466.

Li, X., Cao, W., Su, Y., 2012. A statistical damage constitutive model for softening behavior of rocks, Eng. Geol. 143-144, 1-17.

Liu, Q., Liu, K., Zhu, J., Lu, X., 2014. Study of mechanical properties of raw coal under high stress with triaxial compression. Chin. J. Rock Mech. Eng. 33(1), 24-34.

Lu, Y., Wang, L., Yang, F., 2010. Post-peak strain softening mechanical properties of weak rock. Chin. J. Rock Mech. Eng. 29(3), 640-648.

Ma, L., Xu, H., Tong, Q., Dong, L., Zhang, N., Li, J., 2014. Post-yield plastic frictional parameters of a rock salt using the concept of mobilized strength. Eng. Geol. 177, 25-31.

Peng, J., Cai, M., Rong, G., Yao, M.D., Jiang, Q.H., Zhou, C.B., 2017. Determination of confinement and plastic strain dependent post-peak strength of intact rocks. Eng. Geol. 218, 187-196.

Saksala, T., Ibrahimbegovic, A., 2014. Anisotropic viscodamage-viscoplastic consistency constitutive model with a parabolic cap for rocks with brittle and ductile behaviour. Int. J. Rock Mech. Min. Sci. 70, 460-473.

Shen, H., Wang, S., Liu, Q., 2014. Simulation of constitutive curves for strain-softening rock in triaxial compression. Rock Soil Mech. 35(6), 1647-1654.

Tiwari, R.P., Rao, K.S., 2006. Post failure behaviour of a rock mass under the influence of triaxial and true triaxial confinement. Eng. Geol. 84, 112-129. 
Troncone, A., Conte, E., Donato, A., 2014. Two and three-dimensional numerical analysis of the progressive failure that occurred in an excavation-induced landslide. Eng. Geol. 183, 265-275.

Tutluoğlu, L., Öge, İ.F., Karpuz, C., 2015. Relationship between pre-failure and post-failure mechanical properties of rock material of different origin. Rock Mech. Rock Eng. 48, $121-141$.

Varas, F., Alonso, E., Alejano, L., Fdez-Manin, G., 2005. Study of bifurcation in problem of unloading a circular excavation in a strain-softening material. Tunn. Undergr. Sp. Technol. 20(4), 311-322.

Walton, G., Arzua, J., Alejano, L.R., Diederichs, M.S., 2015. A laboratory-testing-based study on the strength, deformability, and dilatancy of carbonate rocks at low confinement. Rock Mech. Rock Eng. 48(3), 941-958.

Wang, J.A., Park, H.D., 2002. Fluid permeability of sedimentary rocks in a complete stress-strain process. Eng. Geol. 63, 291-300.

Wu X., Jiang Y., Li B., 2018a Influence of joint roughness on the shear behaviour of fully encapsulated rock bolt. Rock Mech. Rock Eng. 51(3): 953-959.

Wu X., Jiang Y., Guan Z., Wang G., 2018b. Estimating the support effect of the energy-absorbing rock bolt based on the mechanical work transfer ability, Int. J. Rock Mech. Min. Sci. 103: 168-178.

Yang, S.Q., Jiang, Y.Z., Xu, W.Y., Chen, X.Q., 2008. Experimental investigation on strength and failure behavior of pre-cracked marble under conventional triaxial compression. Int. J. Solids Struct. 45, 4796-4819.

You, M., Su, C., Gou, Y., 2007. Experimental study on strength and deformation properties of hollow cylindrical specimens of marbles. Chin. J. Rock Mech. Eng. 26(12), 2420-2429.

Zhou, H., Yang, F., Zhang, C., Xu, R., Zhang, K., 2012. An elastoplastic coupling mechanical model for marble considering confining pressure effect. Chin. J. Rock Mech. Eng. 31(12), 2389-2399.

Zimbardo, M., 2016. Mechanical behaviour of Palermo and Marsala calcarenites (Sicily), Italy. Eng. Geol. 210(5), 57-69.

Zhang, Q., Zhang C., Jiang B., Li N., Wang Y., (2018) Elastoplastic coupling solution of circular openings in strain-softening rock mass considering pressure-dependent effect. International Journal of Geomechanics, 18(1), 04017132 


\section{Appendix A. Strength parameters for different kinds of rocks}

The strength parameters for different kinds of marble, mudstone, limestone, coal and sandstone were presented in Tables A1-A9.

Table A.1 Estimation of the equivalent residual strength of Marble T2b (data from Zhou et al. (2012))

\begin{tabular}{ccccc}
\hline $\begin{array}{c}\text { Confining } \\
\text { pressure }\end{array}$ & $\begin{array}{c}\text { Peak } \\
\text { strength }\end{array}$ & $\begin{array}{c}\text { Residual } \\
\text { strength }\end{array}$ & $\begin{array}{c}\text { Equivalent } \\
\text { peak strength }\end{array}$ & $\begin{array}{c}\text { Equivalent } \\
\text { residual strength }\end{array}$ \\
\hline 0 & 162 & 50 & 160.25 & 50.00 \\
5 & 170 & 70 & 160.25 & 57.55 \\
10 & 186 & 92 & 160.25 & 67.10 \\
20 & 210 & 135 & 160.25 & 85.20 \\
40 & 260 & 225 & 160.25 & 125.40 \\
\hline
\end{tabular}

Table A.2 Estimation of the equivalent residual strength of Fine crystal marble (data from You et al. (2007))

\begin{tabular}{ccccc}
\hline $\begin{array}{c}\text { Confining } \\
\text { pressure }\end{array}$ & $\begin{array}{c}\text { Peak } \\
\text { strength }\end{array}$ & $\begin{array}{c}\text { Residual } \\
\text { strength }\end{array}$ & $\begin{array}{c}\text { Equivalent } \\
\text { peak strength }\end{array}$ & $\begin{array}{c}\text { Equivalent } \\
\text { residual strength }\end{array}$ \\
\hline 0 & 48 & 2 & 55 & 2.00 \\
5 & 73 & 28 & 55 & 14.40 \\
10 & 86 & 64 & 55 & 36.80 \\
20 & 110 & 100 & 55 & 45.60 \\
40 & 162 & 162 & 55 & 53.20 \\
\hline
\end{tabular}

Table A.3 Estimation of the equivalent residual strength of Medium crystal marble (data from You et al.

(2007))

\begin{tabular}{ccccc}
\hline $\begin{array}{c}\text { Confining } \\
\text { pressure }\end{array}$ & $\begin{array}{c}\text { Peak } \\
\text { strength }\end{array}$ & $\begin{array}{c}\text { Residual } \\
\text { strength }\end{array}$ & $\begin{array}{c}\text { Equivalent } \\
\text { peak strength }\end{array}$ & $\begin{array}{c}\text { Equivalent } \\
\text { residual strength }\end{array}$ \\
\hline 0 & 65 & 2 & 65.12 & 2.00 \\
5 & 81 & 38 & 65.12 & 22.37 \\
10 & 95 & 72 & 65.12 & 40.74 \\
20 & 128 & 115 & 65.12 & 52.47 \\
30 & 162 & 156 & 65.12 & 62.21 \\
40 & 188 & 186 & 65.12 & 60.95 \\
\hline
\end{tabular}

Table A.4 Estimation of the equivalent residual strength of Coarse marble (data from Yang et al. (2008))

\begin{tabular}{ccccc}
\hline $\begin{array}{c}\text { Confining } \\
\text { pressure }\end{array}$ & $\begin{array}{c}\text { Peak } \\
\text { strength }\end{array}$ & $\begin{array}{c}\text { Residual } \\
\text { strength }\end{array}$ & $\begin{array}{c}\text { Equivalent } \\
\text { peak strength }\end{array}$ & $\begin{array}{c}\text { Equivalent } \\
\text { residual strength }\end{array}$ \\
\hline 0 & 68 & 4 & 74 & 4.00 \\
5 & 90 & 45 & 74 & 31.00
\end{tabular}


590

591

592

593

594

\begin{tabular}{ccccc}
10 & 108 & 77 & 74 & 49.00 \\
20 & 131 & 116 & 74 & 60.00 \\
30 & 155 & 144 & 74 & 60.00 \\
\hline
\end{tabular}

Table A.5 Estimation of the equivalent residual strength of Marble (data from Shen et al. (2014))

\begin{tabular}{ccccc}
\hline $\begin{array}{c}\text { Confining } \\
\text { pressure }\end{array}$ & $\begin{array}{c}\text { Peak } \\
\text { strength }\end{array}$ & $\begin{array}{c}\text { Residual } \\
\text { strength }\end{array}$ & $\begin{array}{c}\text { Equivalent } \\
\text { peak strength }\end{array}$ & $\begin{array}{c}\text { Equivalent } \\
\text { residual strength }\end{array}$ \\
\hline 10 & 102.4 & 65.3 & 85.17 & 41.64 \\
20 & 135.8 & 109.5 & 85.17 & 62.18 \\
40 & 188 & 165.7 & 85.17 & 71.07 \\
60 & 224.5 & 216.6 & 85.17 & 74.65 \\
70 & 248.3 & 246.3 & 85.17 & 80.69 \\
\hline
\end{tabular}

Table A.6 Estimation of the equivalent residual strength of Shanxi mudstone (data from Lu et al. (2010))

\begin{tabular}{ccccc}
\hline $\begin{array}{c}\text { Confining } \\
\text { pressure }\end{array}$ & $\begin{array}{c}\text { Peak } \\
\text { strength }\end{array}$ & $\begin{array}{c}\text { Residual } \\
\text { strength }\end{array}$ & $\begin{array}{c}\text { Equivalent } \\
\text { peak strength }\end{array}$ & $\begin{array}{c}\text { Equivalent } \\
\text { residual strength }\end{array}$ \\
\hline 0 & 21.1 & 8.9 & 24.45 & 8.90 \\
5 & 31.4 & 18.2 & 24.45 & 12.78 \\
10 & 38.1 & 25.7 & 24.45 & 14.86 \\
20 & 47.1 & 35 & 24.45 & 13.32 \\
30 & 54.6 & 48.2 & 24.45 & 15.68 \\
40 & 66.5 & 66.5 & 24.45 & 23.14 \\
\hline
\end{tabular}

Table A.7 Estimation of the equivalent residual strength of Indiana limestone (data from Walton et al. (2015))

\begin{tabular}{ccccc}
\hline $\begin{array}{c}\text { Confining } \\
\text { pressure }\end{array}$ & $\begin{array}{c}\text { Peak } \\
\text { strength }\end{array}$ & $\begin{array}{c}\text { Residual } \\
\text { strength }\end{array}$ & $\begin{array}{c}\text { Equivalent } \\
\text { peak strength }\end{array}$ & $\begin{array}{c}\text { Equivalent } \\
\text { residual strength }\end{array}$ \\
\hline 1 & 67 & 18 & 63.71 & 14.32 \\
2 & 71 & 22 & 63.71 & 14.65 \\
4 & 78 & 33 & 63.71 & 18.30 \\
6 & 87 & 60 & 63.71 & 37.95 \\
8 & 93 & 66 & 63.71 & 36.60 \\
10 & 101 & 75 & 63.71 & 38.24 \\
12 & 107 & 83 & 63.71 & 38.89 \\
\hline
\end{tabular}

Table A.8 Estimation of the equivalent residual strength of Vosges sandstone (data from Besuellea et al.

(2000))

\begin{tabular}{ccccc}
\hline $\begin{array}{c}\text { Confining } \\
\text { pressure }\end{array}$ & $\begin{array}{c}\text { Peak } \\
\text { strength }\end{array}$ & $\begin{array}{c}\text { Residual } \\
\text { strength }\end{array}$ & $\begin{array}{c}\text { Equivalent } \\
\text { peak strength }\end{array}$ & $\begin{array}{c}\text { Equivalent } \\
\text { residual strength }\end{array}$ \\
\hline 10 & 83 & 65 & 67.7 & 44.30
\end{tabular}




\begin{tabular}{ccccc}
20 & 113 & 93 & 67.7 & 51.60 \\
30 & 135 & 114 & 67.7 & 51.90 \\
40 & 150 & 136 & 67.7 & 53.20 \\
50 & 168 & 158 & 67.7 & 54.50 \\
\hline
\end{tabular}

599

600

Table A.9 Estimation of the equivalent residual strength of typical coal samples (data from Liu et al. (2014))

\begin{tabular}{ccccc}
\hline $\begin{array}{c}\text { Confining } \\
\text { pressure }\end{array}$ & $\begin{array}{c}\text { Peak } \\
\text { strength }\end{array}$ & $\begin{array}{c}\text { Residual } \\
\text { strength }\end{array}$ & $\begin{array}{c}\text { Equivalent } \\
\text { peak strength }\end{array}$ & $\begin{array}{c}\text { Equivalent } \\
\text { residual strength }\end{array}$ \\
\hline 0 & 23 & 1 & 30.71 & 1.00 \\
10 & 62 & 32 & 30.71 & 5.69 \\
20 & 87 & 63 & 30.71 & 10.37 \\
30 & 114 & 95 & 30.71 & 16.06 \\
40 & 135 & 116 & 30.71 & 10.74 \\
50 & 158 & 146 & 30.71 & 14.43 \\
\hline
\end{tabular}

601 


\section{Appendix B. Implementation of the new constitutive model by numerical tests}

In order to verify the new constitutive model, some numerical simulations were conducted to reproduce the post-failure behavior of the rocks by FLAC $^{3 \mathrm{D}}$ code. The new model in the numerical simulations was developed based on the strain-softening model by the Fish language in FLAC ${ }^{3 \mathrm{D}}$. The transitional strength was updated according to the stress and deformation state of every element after every step. The modified strain-softening constitutive laws in FLAC $^{3 \mathrm{D}}$ were characterized by six parameters: bulk modulus $K$, shear modulus $G$, friction angle $\phi$, cohesion $c$, dilation angle $\psi$, softening parameter $\eta$ and the two new parameters $\beta$ and $\gamma$.

The performance of the present model was demonstrated at the material point level using a computational model of a single 8-node cube element. The model size is $1 \mathrm{~m} \times 1 \mathrm{~m} \times 1 \mathrm{~m}$. The material properties of Tennessee marble and model parameters given in Table B1 were used throughout simulations. The confining pressures were set to be $0 \mathrm{MPa}, 27.6 \mathrm{MPa}, 34.5 \mathrm{MPa}$, 48.3 $\mathrm{MPa}$ in different tests. Compressive axial loading was applied in the form of a velocity boundary condition with a constant velocity of $-5 \times 10^{-7} \mathrm{~m} / \mathrm{s}$ on the upper surfaces.

The numerical test results at different confining pressure are shown in Fig. B.1. To highlight the advantages of the new model, the stress-strain curves with the conventional strain-softening model and results from the laboratory experiments are also depicted in these figures. A better agreement was observed between numerical results with the new model and the experiment data in these figures.

At the condition of $\sigma_{3}=0 \mathrm{MPa}$, the rock behaviour with different model are all the same, and close to the experiment data. It is reasonable as no confining pressure is applied, resulting no effect on the residual strength. With the increasing of confining pressure, the advantages of the new model becomes more and more obvious. 
626

627

628

629

630

631

632

633

634

635

636

637

638

639

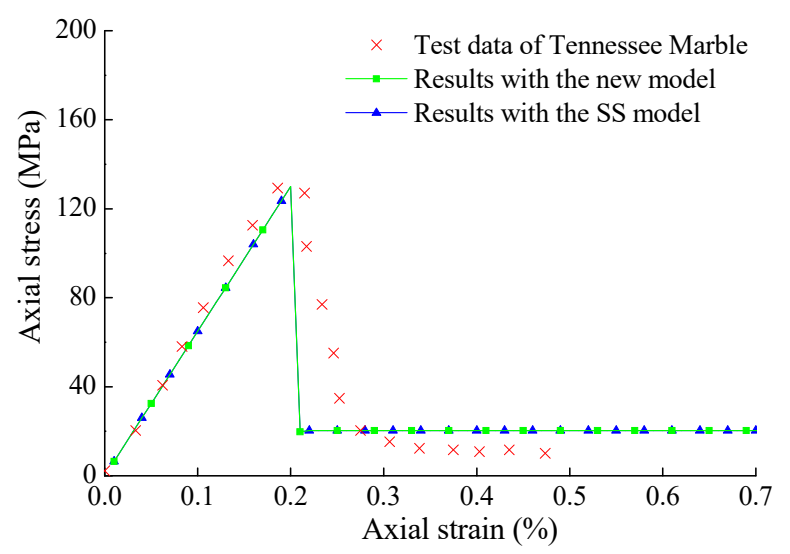

(a)

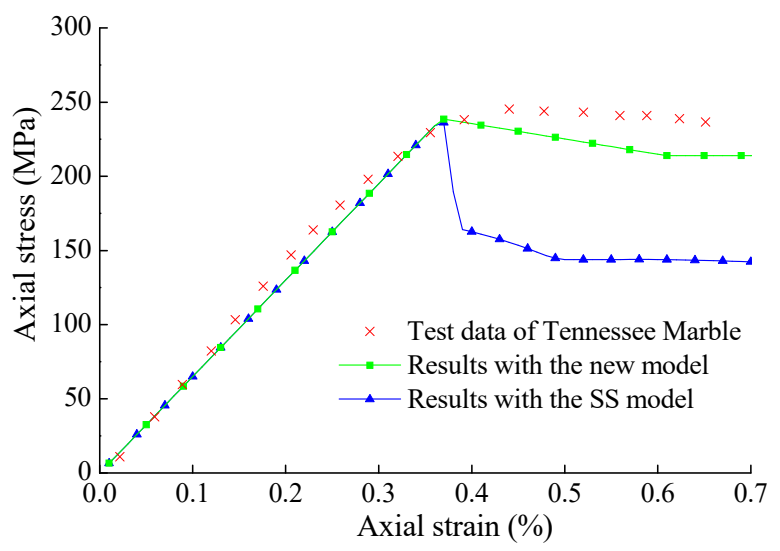

(c)

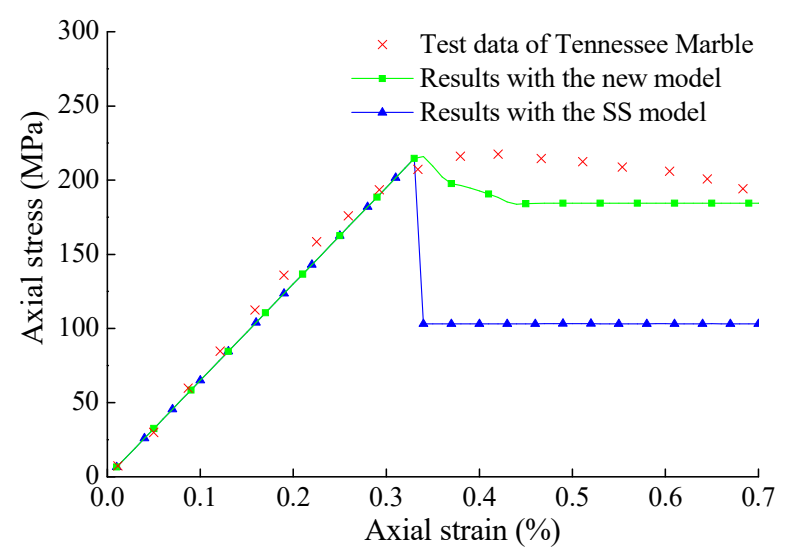

(b)

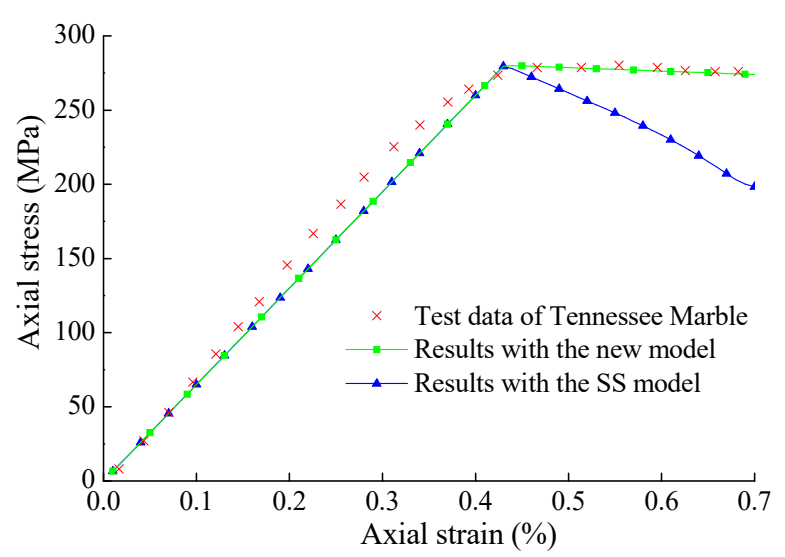

(d)

Fig. B.1 Comparison between experimental and theoretical curves at different confining pressures:

(a) $\sigma_{3}=0 \mathrm{MPa}$; (b) $\sigma_{3}=27.6 \mathrm{MPa}$; (c) $\sigma_{3}=34.5 \mathrm{MPa}$; (d) $\sigma_{3}=48.3 \mathrm{MPa}$.

Table B.1 The properties of Tennessee marble employed in the verification case

\begin{tabular}{ccccccccc}
\hline$E / \mathrm{GPa}$ & $v$ & $K_{p}$ & $K_{\psi}$ & $\sigma_{c}(0) / \mathrm{MPa}$ & $\sigma_{c}^{*}(0) / \mathrm{MPa}$ & $\alpha$ & $\beta$ & $\gamma$ \\
65 & 0.2 & 3.0 & 1.33 & 138 & 20.3 & 0.005 & $1.15 \mathrm{e} 8$ & 0.0044 \\
\hline
\end{tabular}

